\title{
Effect of Synthesized Chitosan Flame Retardant On Flammability, Thermal, And Mechanical Properties of Vinyl Ester/Bamboo Nonwoven Fiber Composites
}

Prabhakar M.N. ( $\nabla$ dr_prabhakar@changwon.ac.kr)

Changwon National University

K Venkata Chalapathi

Changwon National University

Ur Rehman Shah Atta

Changwon National University

Jung-il Song

Changwon National University

Research Article

Keywords: Chitosan, Vinyl ester, Bamboo fibers, Thermal stability, Flame retardant

Posted Date: July 27th, 2021

DOl: https://doi.org/10.21203/rs.3.rs-723535/v1

License: (c) (i) This work is licensed under a Creative Commons Attribution 4.0 International License.

Read Full License 


\section{Abstract}

In this study, chitosan-based bio-flame retardant additive (referred to as NCS) was prepared by altering the chitosan (CS) chemically with silica (S) via ion interchange reaction and studied the effect on flame retardant, thermal and mechanical properties of vinyl ester/bamboo fiber (VE/BF) composites manufactured by the vacuum assisted resin transfer molding (VARTM) process. Fourier transform infrared spectroscopy (FTIR), scanning electron microscopy (SEM) and X-ray diffraction (XRD) analysis used to characterize the NCS. The spectral results revealed a new peak at $1560 \mathrm{~cm}^{-1}$ corresponding to $\mathrm{NH}_{3}{ }^{+}-{ }^{-} \mathrm{O} \mathrm{Si}$, bring up the interactive bond between CS and S. SEM, and XRD showed the diverse morphology (coarse surface), and significant decrement in the intensity of diffraction patterns respectively support further the formation of NCS. The heat release rate of NCS decreased significantly by $76 \%$, and residual char increased by $47 \%$ compared with chitosan. The flame retardant and thermal behavior of NCS-VE/BF composites were examined by UL-94 standards, micro and cone calorimeter and thermogravimetric analysis. The results showed a delay in burning time in UL-94, enhanced LOI \% and decrement of peak heat release rate and total heat release rate compared to pure composites by 32,14 , and $18 \%$, respectively. The residual char increased by $47 \%$. The mechanical properties also improved satisfactorily. Overall, the synthesized NCS could be suitable for the fabrication of sustainable flameretardant natural fiber composite without deterioration of mechanical properties that are suitable for substructural parts in engineering applications.

\section{Introduction}

Natural fibers (NFs), similar to a composite, with cellulose, hemicellulose, and lignin as reinforcements act as matrices structurally and present unique properties. Hence, NFs play a vital role in reinforcements for composites for engineering applications (Kuranchie et al. 2021). Automobile and aerospace industries have already started using NF composites for structural and substructural parts because of their low density, good mechanical strength, vibration absorption, and ultraviolet ray blocking (Kumar 2020; Lau et al. 2018). The advancements in NFs toward automobile application has been introduced in the driver and front passenger doors and the rear wing of the new 718 Cayman GT4 Clubsport production vehicles of Porsche's (bioconcept cars). These are formed of an NF composite from economic and energy perspectives (Porsche Newsroom 2019).

The NF cannot withstand fire and are thermally weak. However, although NFs have sufficient mechanical strength and are competitive with synthetic fibers, such as carbon and glass fibers, they cannot control the flammability properties of polymer composites as reinforcements (Elsabbagh et al. 2018). The incorporation of flame retardant (FR) additives are the most common approach for improving the flame retardancy of NF composites and various types of FR additives, including ammonium polyphosphate, magnesium hydroxide, zinc borate, and silicon dioxide, have already been studied (Shukor et al. 2014; Sain et al. 2004; Wu et al. 2020). However, their inclusion predominately interferes with the mechanical properties because of their lack of interfacial chemical bonding with both the matrix and reinforcement, 
thereby creating stress concentration points. Hence, improving the fire resistance and strength maintenance are challenging tasks for researchers and industries for the usage of NF composites.

Recently, a few research studies have focused on modifying the chemical interaction of FR with either the $\mathrm{NF}$ reinforcement or matrix to enhance the flame resistance of NF composites without significantly affecting their mechanical properties (Khalili et al. 2017; Kim et al. 2020; Jeencham et al. 2014). Research is still required in this area due to the demand of the present market and the necessity to achieve desired properties effectively. Bio-FRs can serve this objective, consisting of biomass that provides dense char during combustion; hence they are drawn attention due to green sources and environmentally friendly characteristics compared with existing FRs showing health and environmental hazards, liberating corrosive gasses, etc [Costes et al. 2017]. However, Bio-FRs did not show high efficiency for polymers and need to be functionalized effectively by chemical modification. Moreover, the selection of a suitable biobased material for flame retardancy and chemical modification is critical. A few biomaterials are available as waste that can enhance flame retardancy, e.g., chitosan, lignin, bone powder, oyster shell powder, and eggshell powder.

Among, chitosan is an exciting and abundant biowaste polymer that can be easily chemically modified by grafting copolymerization and compounding due to the chemical structure of an amino polysaccharide. The multi hydroxyl and amidogen groups present in chitosan promote flame retardancy behavior. In addition, chitosan has been used as a char-forming agent in intumescent systems. Recently, Prabhakar et al. used chitosan in a thermoplastic starch/flax fabric (TPS/FF) system and effectively improved its thermal and flame retardancy properties to reach those of commercial FRs with satisfactory improvements in its mechanical properties (Prabhakar and Song 2018). In their further studies, a novel FR compound produced by effective modification of chitosan with ammonium polyphosphate could significantly enhance the flame retardancy properties of NF composites (Prabhakar et al. 2019; Prabhakar and Song 2020; Shao et al. 2021). Different FRs are used for the modification of chitosan, as established in the literature (Li et al. 2020).

Silicon dioxide is an inorganic material with interesting properties such as low toxicity, good biocompatibility, high versatility, high surface area, uniform porosity, and remarkable chemical and thermal stability (Wang et al. 2020; Huang et al. 2019). In addition, silicon dioxide can act as an effective FR for polymer composites, by condensing the phase and forming an inorganic char, and for wood fiber polymer composites, decreasing the heat release rate (HRR) and total heat release rate (THR) (Pan et al. 2014). Therefore, silicon dioxide gained attention for commercial applications in civil engineering, construction, building, electrical, transportation, aerospace, defense, textile, and cosmetic industries (Hamdani et al. 2009). Moreover, silicon dioxide alone may be able to play a dual role of enhancing the mechanical and flame retardancy properties of NF composites.

Considering the above, this study focused on the preparation of a novel FR additive (referred to as NCS) by a simple chemical approach using chitosan and silicon dioxide. Although the combination of chitosan and silicon dioxide has been studied for other research areas, such as the removal of $\mathrm{GO}$, there is no 
information available on the synthesis of a chitosan-based silicon dioxide FR additive (NCS). Therefore, this study further investigated its effect on NF polymer (vinyl ester/bamboo fiber (VE/BF)) composites. The chemical features of the synthesized NCS compounds were characterized via scanning electron microscopy (SEM), Fourier transform infrared (FTIR) spectroscopy, X-ray diffraction (XRD), thermogravimetric analysis (TGA), and microcalorimetry. The flammability, thermal, and mechanical properties of the NCS additive-incorporated VE/BF composites were examined via horizontal burn test (HBT), cone calorimetry, TGA, XRD, FTIR, and universal testing machine (UTM). This study aim to introduce a chitosan-based FR additive in NF composites to support flame retardancy and mechanical strength.

\section{Experimental Methods}

\subsection{Materials}

The following chemicals were used in this study without any modifications: VE (viscosity $150 \mathrm{cps}$ and specific gravity 1.03), methyl ethyl ketone peroxide (MEKP), cobalt naphthalate (CN), and Teflon sheets (CCP composites, Korea); bamboo nonwoven fabric (45.1 MPa, reinforced size: $200 \times 200 \times 0.39 \mathrm{~mm}$ (Sungchang Industries, Korea)). Chitosan (molecular weight 600,000, viscosity 50-800 mPa, degree of deacetylation 80-95\% (Kwang Jin Chemical Co. Ltd., South Korea); and silicon dioxide (extra pure) (Smachun Chemical Co., Korea).

\subsection{Preparation of NCS}

First, the required amount of chitosan flakes $(10 \mathrm{w} / \mathrm{v})$ was dispersed in $2 \%$ acetic acid solution with ultrapure water under $500 \mathrm{rpm}$ stirring conditions for $4 \mathrm{~h}$ at $60^{\circ} \mathrm{C}$ to obtain a homogenous chitosan solution. Subsequently, added the required amount of silicon dioxide solution $(2.5 \mathrm{w} / \mathrm{v})$ to the chitosan solution (equivalent to the molar ratios of $\mathrm{SiO}_{2}$ in accordance with chitosan), and the stirring was continued at $500 \mathrm{rpm}$ for an $\mathrm{h}$ at $80^{\circ} \mathrm{C}$. The end of the reaction was determined by the formation of a yellowish-brown thick precipitate, and subsequently, cooled to room temperature and subjected to vacuum filtration. The obtained product was thoroughly washed with deionized water, dried overnight ( 6 hrs.) in an oven at $70^{\circ} \mathrm{C}$, and the obtained flakes finely ground into a powder using a ball mill.

\subsection{Manufacture of NCS-VE/BF composites}

The VARTM process was used to manufacture the NCS-VE/BF composites, as discussed by Chalapathi et al. (2020). Six bamboo nonwoven fabrics $(200 \times 200 \times 0.39 \mathrm{~mm})$ and 0.4-MPa vacuum pressure were used in the VARTM process. The infused wet composites were subjected to a pre-curing process at room temperature for $5 \mathrm{~h}$, followed by post-curing at $60^{\circ} \mathrm{C}$ for $3 \mathrm{~h}$ in a composite curing oven (Fleta $5, \mathrm{LK}$ LAB Co., Ltd, Republic of Korea). The overall preparation of NCS and the manufacturing process of the NCSVE/BF composites are demonstrated comprehensively by schematic illustration, as depicted in Scheme 1.

\subsection{Testing and Characterization}




\subsubsection{NCS characterization}

The details of the characterization instruments adopted for analyzing the fabricated NCS compound are as follows: a scanning electron microscope with an ion sputter coater (Model: Emcrafts cube 2, EMCRAFTS Co., Korea) was used for microanalysis. A particle size analyzer (Model: Malvern Mastersizer) was used for particle size analysis. FTIR spectrometer (FT-IR-6300, United Kingdom) using the KBr disk method was employed for spectral analysis. X-ray diffractometer (Model: Bruker, D8 Discover) with Nifiltered $\mathrm{Cu}$ Ka radiation at a speed of $50^{\circ} \mathrm{C} / \mathrm{min}$, current of $30 \mathrm{~mA}$, and range of $0^{\circ}-50^{\circ}$ was used for XRD analysis. A particle size analyzer (Model: Mastersizer 2000, Malvern Panalytical Ltd., United Kingdom) was used to calculate the mean particle size and obtain the particle size distribution. An elemental analyzer (Variable EL, Analyzensysteme GmbH Co., Ltd., Germany) was employed for detecting the elements. A thermogravimetric analyzer (Model: TGA Q600, TA instruments) was used at a heating rate of $20^{\circ} \mathrm{C} /$ min under an inert atmosphere with a temperature range of $30^{\circ} \mathrm{C}-700^{\circ} \mathrm{C}$ for thermal analysis. $\mathrm{A}$ microcalorimeter test apparatus (Model: Micro Calorimeter (Federal Aviation Administration, Fire Testing Technology (FTT), United Kingdom)) was utilized to calculate the heat release and THR rates as per ASTM D 7309 standards.

\subsubsection{NCS-VE/BF composites characterization}

The details of the testing instruments for analyzing the fabricated NCS-VE/BF composites are as follows: a universal testing machine (Model: R\&R, Inc., Korea) was used for conducting tensile $(250 \times 25$ $\times 3 \mathrm{~mm}$ ) and flexural (support span $64 \mathrm{~mm}$ (16 times the thickness)) tests according to ASTMD638 and ASTMD 790-03 standards, respectively. An Izod impact instrument (QC-639F, Cometech Testing Machine Co., Ltd., China) with an 11-J impact hammer was used for conducting impact tests. A cone calorimeter (Fire Testing Technology, United Kingdom) was employed according to ASTM E 1354/ISO 5660 standard $(100 \times 100 \times 3 \mathrm{~mm})$ at $50 \mathrm{~kW} / \mathrm{m}^{2}$ to obtain, the external heat flux for examining the flammability and smoke properties.

\section{Results And Discussion}

\subsection{Experimental results for NCS}

\subsubsection{Spectral analysis}

The spectral peaks of NCS and the related raw materials, chitosan and silicon dioxide additives, are shown in Fig. 1. In the chitosan spectrum, the spectral peaks appear at 3500-3300, 1620, 1430,1378, 1160,1079 , and $1032 \mathrm{~cm}^{-1}$, corresponding to $-\mathrm{OH}$ and $-\mathrm{NH}_{2}, \mathrm{C}=\mathrm{O}, \mathrm{O}-\mathrm{H}, \mathrm{C}-\mathrm{N}$ (amide), $\mathrm{C}-\mathrm{O}$ (bridge oxygen), (C-O-C assym), and (C-O-C sym) (Lustriane et al. 2018). Besides the silicon dioxide spectrum, the peaks appearing at 1051 and 781 and $1600-1700 \mathrm{~cm}^{-1}$ correspond to the bending vibrations of $\mathrm{Si}-$ $\mathrm{O}$ and $-\mathrm{OH}$, respectively. In contrast, the synthesized NCS compound exhibits the spectral peaks of both raw compounds, chitosan, and silicon dioxide, at 3427 and 1079, 776, and $683 \mathrm{~cm}^{-1}$. Most importantly, 
new peaks appeared at 1628 and $1560 \mathrm{~cm}^{-1}$, suggested a chemical bond may be formed between chitosan and silicon dioxide by $\mathrm{NH}_{3}{ }^{+}{ }^{-}{ }^{-} \mathrm{O}$ Si (Hassan etal. 2019; Budnyak et al. 2014). It is evident that the spectral peaks disappeared at 891 and $762 \mathrm{~cm}^{-1}$, revealing a combined interaction of silica and chitosan (Yeh et al. 2007). In addition, the broad peaks of chitosan at 2917 and $2849 \mathrm{~cm}^{-1}$ become sharp, and at $1382 \mathrm{~cm}^{-1}$ shifts to $1406 \mathrm{~cm}^{-1}$. Notably, the intense bond at $1079 \mathrm{~cm}^{-1}$ may be associated with Si-0$\mathrm{Si}$ and $\mathrm{Si}-\mathrm{O}-\mathrm{C}$, suggesting interaction bond formation. Overall, the FTIR spectrum suggested the ion exchange reaction between chitosan and silicon dioxide to form NCS compound and further strengthened by XRD and SEM analysis discussed in the following sections.

\subsubsection{XRD analysis}

The XRD patterns of NCS and the corresponding raw materials chitosan and silicon dioxide are shown in Fig. 2(A). Silicon dioxide exhibits well-defined sharp diffraction peaks at 20.8 ${ }^{\circ}, 26.6^{\circ}, 36.5^{\circ}, 42.4^{\circ}, 45.5^{\circ}$, and $49.9^{\circ}$, clearly indicating a crystalline structure (Kumar and Koh 2012). Chitosan presented typical semi-crystalline peaks at approximately $10^{\circ}$ and $20^{\circ}$ (Zang, Yan, Shen, Fang, Zhang, Wang, \& Zhang, 2014). Conversely, the NCS compound totally diverse from CS and exhibited sharp crystalline diffraction peaks at $20.8,26.6,36.5,39.4,40.2,42.4$, and $45.8^{\circ}$, almost similar to silicon dioxide. Moreover, the intensities of the main two peaks of silicon dioxide at $20.8^{\circ}$ and $26.6^{\circ}$ are having 20978 and 106065 , which are drastically decreased in the NCS compound to 16345 and 66383. Further, the calculated crystalline diameter (inserted table in Fig. 2(A)) of NCS showed $47 \mathrm{~nm}$, but CS and $\mathrm{SiO}_{2}$ having 2.27 and $55.75 \mathrm{~nm}$, respectively. Overall, the obtained diffraction patterns of NCS may conclude the structure difference by the chemical reaction between CS and S to form the NCS compound.

\subsubsection{Microanalysis}

Micro images of NCS and the corresponding raw materials chitosan and silicon dioxide additives are shown in Fig. 2(B). Silicon dioxide particles showed smooth metallic surface morphology without any voids. The particles varied the size, majorly two types of particle sizes are observed in the micrograph, i.e., $\sim 2-10 \mu \mathrm{m}$ and $\sim 10-20 \mu \mathrm{m}$. Chitosan exhibited a rough and continuous morphology without voids. However, in NCS, the micrograph showed an entirely different morphology than CS, and S compound confirms the reaction between them. The shape of the particles seems slightly in between the trend of CS and $\mathrm{S}$, but the course surface with continuous morphology without voids could be observed. In addition, 2-5 $\mu \mathrm{m}$ sized particles are stick to the surfaces of larger-sized particles and form lumps in between them. The NCS particles are also of two types of sizes, similar to silicon dioxide particles. In conclusion, the morphology of NCS showed a clear difference in morphology than CS and S might help to understand further and support the aforementioned FTIR and XRD analysis.

\subsubsection{Particle size analysis}

The particle size distribution of the NCS additive is shown in Fig. 2(C). Two average particle sizes of NCS were approximately 100 and $1000 \mu \mathrm{m}$, with volume percentages of 2 and 24, respectively. The mechano ball mill process interestingly produced a precise NCS particle size of about $1258 \mu \mathrm{m}$ at $22 \%$ volume. 


\subsubsection{Elemental analysis}

The composition of chitosan and the NCS compound elements include carbon, hydrogen, nitrogen, and sulfur, tabulated in Fig. 2(D). From the table, chitosan has the main elements of $\mathrm{C}, \mathrm{H}$, and $\mathrm{N}$ with $42 \%$, $6.88 \%$, and $8.17 \%$ content, respectively. Besides, the synthesized NCS compound showed similar to chitosan elements, i.e., $\mathrm{C}, \mathrm{H}$, and $\mathrm{N}$; however, a significant reduction could be observed in the values, $22.33 \%, 5.12 \%$, and $3.38 \%$, respectively. In addition, $0.46 \%$ of silicon element can be seen in the table representing silicon moiety obtained by the chemical reaction with $\mathrm{SiO}_{2}$. Hence, the elemental analysis further strengthens the spectral and diffraction analysis to form the NCS compound.

\subsubsection{Thermal analysis}

The thermograms of chitosan and NCS additive are shown in Fig. 3(A). Chitosan exhibited a two-step degradation process in the thermogram; the initial step at $<100^{\circ} \mathrm{C}$ was due to the exclusion of the absorbed water. The prominent pyrolytic degradation of the chitosan molecule was observed at $350^{\circ} \mathrm{C}$ and continued to $700^{\circ} \mathrm{C}$ owing to dehydration of saccharide rings and decomposition of the acetylate and deacetylate units. The multihydroxyl group present in chitosan formed a dense char of almost $30 \%$ at $700^{\circ} \mathrm{C}$. Besides, the NCS compound showed a very different trend in thermograms, and the thermal degradation progressed as a single-step process. Initial decomposition temperatures at around $100^{\circ} \mathrm{C}$ maintained constant weight without degradation, and the weight loss occurred after $100^{\circ} \mathrm{C}$, and the degradation proceeded with a marginal decrement in the weight loss. The maximum degradation occurred above $300^{\circ} \mathrm{C}$ with weight loss of around $20 \%$; in chitosan, the \% was almost 60 , which clearly refers to the significant slowdown of the thermal degradation process due to the synergistic effect of the silicon and chitosan. It may be understood, in the thermal degradation process, the silicon moiety present in the NCS protects the material from thermal degradation. In addition, NCS produced nearly $56 \%$ char residue at $700^{\circ} \mathrm{C}$ showing substantial thermal stability. The chitosan and silica moieties present in NCS probably produce a carbonaceous and silica-based char residue.

The oxidative thermal degradation of NCS is shown in Fig. 3( $\left.\mathbf{A}_{1}\right)$. As can be observed from the figure, the thermal oxidation of NCS occurs in two steps in the $30-400^{\circ} \mathrm{C}$ temperature range. Almost $20 \%$ of weight loss occurred at initial degradation temperature $>240^{\circ} \mathrm{C}$ without decline so drastic. After that, a drastic thermal degradation occurred, directly resembling chitosan in the nitrogen atmosphere, which refers to the degradation of saccharide rings. However, after $400^{\circ} \mathrm{C}$, the slowdown of thermal degradation could be seen; almost $15 \%$ of weight loss occurred until $580^{\circ} \mathrm{C}$. Interestingly even at elevated temperatures from 580 to $700^{\circ} \mathrm{C}$ around the thermal degradation stopped, no further weight loss occurred and formed almost $37 \%$ char residue showed significant thermal stability under air atmosphere.

\subsubsection{HRR analysis}

The HRR peaks of chitosan and the NCS additive are shown in Fig. 3(B). From the figure, it can be observed that both CS and NCS produced two pHRR peaks during the combustion analysis. Chitosan burned rapidly during microcalorimetry analysis refers to the sensitivity with the fire and produced the 
highest pHRR with a value of $61.9 \mathrm{~kW} / \mathrm{g}$ at $321^{\circ} \mathrm{C}$. The second pHRR peak was also generated with the value of $18 \mathrm{~kW} / \mathrm{g}$ at $538^{\circ} \mathrm{C}$ due to thermal stresses. Remarkably, NCS showed changed flammability behavior than $\mathrm{CS}$. The synergistic effect of $\mathrm{CS}$ and $\mathrm{SiO}_{2}$ effectively decreased by showing the pHRR value $14.9 \mathrm{~kW} / \mathrm{g}$, which refers to the severe decrement of pHRR about $75 \%$ compared with CS with an equal amount of flame retardant [Shao 2014]. Moreover, the delayed temperature of about $10^{\circ} \mathrm{C}$ could be observed for the generated pHRR peak, further supporting the flammability property of the NCS compound. Crack formation due to thermal stress also happened in NCS due to dense char, although it is almost $90 \mathrm{C}$ later than CS. Overall, a significant improvement is achieved in the flammability property of the NCS compound owing to the production of the dense char from the synergistic effect of the silicon dioxide and chitosan moieties through the condensed phase.

\subsection{Experimental results for NCS-VE/BF composites 3.2.1. Spectral (FTIR) analysis}

A spectral (FTIR) analysis is performed to verify the interaction (chemical or physical) between NCS and the VE/BF composites. The spectral analysis data of VE/BF and various \% of NCS-VE/BF composites are shown in Fig. 4(A) and Supplementary section SI Fig. 1. The VE/BF composite spectrum consists of the combined spectral peaks of VE and BF at 1713,2920 , and $1032 \mathrm{~cm}^{-1}$ corresponding to the carboxyl group of ester, methyl groups $(\mathrm{C}-\mathrm{H})$, and glucopyranose rings $(\mathrm{C}-\mathrm{O})$. Notably, the spectral peak intensity at $1713 \mathrm{~cm}^{-1}$ is increased, clearly signifying the presence and interaction of BF with VE (Sefadi and Luyt 2012). On the addition of the NCS additive to the VE/BF composites, no apparent chemical changes occur in the composites, as shown in the spectrum (Fig. 3B). The combined spectral peaks of VE and BF in the VE/BF composite persists in NCS-VE/BF composites. In fact, several apparent changes occurred in the spectrum of VE/BF composites after the addition of NCS. For instance, the disappearance of spectral peaks at 910 and $1644 \mathrm{~cm}^{-1}$, the spectral peak at approximately $3400 \mathrm{~cm}^{-1}$ corresponding to the $-\mathrm{OH}$ groups slightly shifted to higher wavenumbers with the percentage increase in NCS and the formation of a new peak at $797 \mathrm{~cm}^{-1}$. Hence, these spectral alternations might be evidence for the interaction effect of NCS on the VE/BF composites.

\subsubsection{XRD analysis}

The XRD patterns of the VE/BF and NCS-VE/BF composites are shown in Fig. 4(B). The VE/BF composite shows a broad peak at approximately $19.9^{\circ}$ with an intensity of 6215 counts. It suggests the non-crystallinity of the VE/BF composite with an amorphous structure. Whereas, the addition of the NCS additive significantly influences the structural behavior of the VE/BF composites. It can be observed that sharp XRD peaks appear at 20.8, 26.6 (predominate), 36.5, 39.4, and $42.4^{\circ}$ for the $2 \mathrm{wt} . \%$ NCS-loaded $\mathrm{VE} / \mathrm{BF}$ composite, which gradually becomes predominant with increasing percentage of NCS. These sharp peaks exhibit the induced effect of the NCS crystalline structure and the intensity of the peaks could be clearly observed in the figure at $6 \%$ NCS-VE/BF composite spectrum. The appearance of the NCS crystalline peaks also indicates that the powder particles are distributed homogeneously throughout the 
VE/BF composite. Overall, the XRD results further strengthen the spectral analysis for the interaction of NCS with VE/BF composites.

\subsubsection{Microanalysis}

The surface and tensile fracture surfaces of the VE/BF and NCS-VE/BF composites were examined by microanalysis, and the micrographs are shown in Fig. 5 . The surface SEM images clear present the differences in the structural morphology of the VE/BF and NCS-VE/BF composites. The VE/BF composites are almost smooth, with some impurities are found to be present everywhere on the surface while cutting the specimen. In comparison, the surface of the 2 wt.\% NCS-loaded VE/BF composites seem coarse, and some of NCS particles covered by the VE resin are observed on the surface. This rough behavior gradually predominates, and even the number of particles on the surface increases with increasing wt.\% of NCS in VE/BF composites. Furthermore, the EDX and EDX mapping support the microanalysis by exhibiting additives and their distribution, as shown in Fig. 5. From the EDX graphs, the presence of 'silicon element in the NCS inclusion and its increment with increasing percentage can be observed, absent in those of the VE/BF composites. These observations strongly support the EDX mapping results shown in the figure.

\subsubsection{Thermal analysis}

The TGA curves of the VE/BF and NCS-VE/BF composites under pyrolytic and oxidative atmospheres are shown in Fig. 6 and important data is tabulated in Table 1. In the pyrolytic atmosphere, the trends of the thermograms are almost similar, with marginal differences in the initial degradation process. An approximately $1 \%$ weight loss occurs below $150^{\circ} \mathrm{C}$, corresponding to the degradation of the sample by the evaporation of free water. The major degradation process under the effect of constituents (zeolites) present in the bamboo fibers, a slight degradation step observed at approximately $350-400^{\circ} \mathrm{C}$, more predominant in the case of the VE/BF composites and marginal for the NCS-VE/BF composites. At the end of the maximum degradation process, the char's mass residue at $700^{\circ} \mathrm{C}$ for the VE/BF and 2,4 , and 6 wt.\% NCS-VE/BF composites are 4.7, 6.8, 8.2, and 9.0\% corresponding. Therefore, the introduction of NCS can accelerate the decomposition of the VE/BF composites by forming about $47 \%$ char residue compared with pure VE/BF that can suppress the release of combustible gases.

In the oxidative atmosphere, the trends of the thermograms are almost similar, and no apparent changes are observed between the VE/BF and NCS-VE/BF composites. However, the VE/BF composites $\left(\sim 350^{\circ} \mathrm{C}\right)$ start major degradation process slightly earlier than that of the NCS-VE/BF composites $\left(\sim 359^{\circ} \mathrm{C}\right)$. This behavior of the VE/BF composites progressively continues at the end of the maximum degradation. In addition, the inclusion of NCS shows an impact, even in small quantities, on maintaining a marginal dominance throughout the degradation process. The VE/BF composites completely combust without leaving any char residue at $700^{\circ} \mathrm{C}$. However, in the case of a high percentage of NCS loading, the VE/BF composites are not combustible and left behind at approximately $1.5 \mathrm{wt} . \%$ stable residues indicating the enhancing thermal stability of the composites even under an oxidative atmosphere.

\subsubsection{Flame retardancy}




\subsubsection{UL-94 (HBT and VBT) and LOI test}

The horizontal burn time and rate data of the VE/BF and NCS-VE/BF composites obtained by the HBT test are tabulated in Table 2. The weak flammability properties of both VE and BFs induce rapid burning of the VE/BF composites with a burn time of $1.53 \mathrm{~min}$. However, the burning time meaningfully increased with the incorporation of NCS into VE/BF composites. Addition of $2 \mathrm{wt} . \%$ NCS delays the burn time to $2.32 \mathrm{~min}$, an approximately $34 \%$ delay compared to that of the VE/BF composites. This trend gradually increases for 4 and 6 wt.\% NCS addition, with delays of 2.35 and 2.54 min, respectively, mainly due to the formation of the char residue, particularly the carbonaceous silicate char, which slow down the propagation of the fire and protected the underlying material (Shen et al. 2014). In addition, the inclusion of NCS into the composites effectively improved the modulus of the composites as discussed in Sect. 3.2.6. The high stiffness leads to heat resistance, which is one of the factors in the fire triangle, and hence, results in a low burning rate (Atta ur Rehman et al. 2018). Besides, the flammability ratings of NCS-VE/BF composites obtained by vertical burn test and LOI results are tabulated in Table 2 . The incorporation of NCS could not make the VE/BF composites reach VB levels; all the composites burnt completely. However, as shown in (supplementary information) SI. Figure 1, the digital images during the vertical burn test exhibited the rate of burning time decreased after incorporation of NCS than VE/BF composites. In addition, the oxygen percentage decently increased with the increasing amount of NCS in VE/BF composites. The $\mathrm{O}_{2} \%$ reasonably increased for 2,4 , and $6 \%$ of NCS in VE/BF composites by 28 , 31 , and $33 \%$, respectively.

\subsubsection{Micro and cone calorimetry analysis}

The microcalorimetry analysis was carried out to obtain the HRR and THR data for further understand the flammability behavior of the NCS-VE/BF composites. The HRR and THR data of the VE/BF and various NCS-loaded VE/BF composites are shown in Fig. 6(B) and tabulated in Table 1. It can be observed from the figure that the attained data are in agreement with the HBT results. The pHRRs of the VE/BF and 2$6 \%$ NCS-VE/BF composites are 422.7, 381.5, 373.6, and $361.9 \mathrm{~W} / \mathrm{g}$, respectively. The inclusion of NCS into the VE/BF composites significantly suppressed the pHRR by approximately $14 \%$, and the reduction gradually continues with an increasing percentage of NCS. Correspondingly, the THR data follow the pHRR trend, showing values of $25.5,24.7,23.3$, and $20.7 \mathrm{kj} / \mathrm{g}$ for the VE/BF and $2-6 \%$ NCS-VE/BF composites. The inclusion of NCS lowers the THR by approximately $18 \%$. In the same way, the fire growth index (FIGRA) (Table 2) indicated the growth profile respectively reduced by 28,31 , and $33 \%$ with the addition of 2, 4, and $6 \%$ of NCS to VE/BF composites. Besides, as shown in SI Fig. 2, the $\mathrm{CO}_{2}, \mathrm{CO}$ and SPR of the NCS-VE/BF composites also reduced slightly around $20 \%$. The reduction in the smoke production rate responsible for the condensed phase could be attributed to the control exerted on the VE/BF composites by the inclusion of NCS. (Song et al. 2014). Hence, the UL-94 test, LOI, micro and cone calorimeter results concluded that, the NCS additive can serve as a flame retardancy for natural fiber polymer composites by a condensed phase arising from carbonaceous char. The plausible flame retardant mechanism of NCS-VE/FF composite during the combustion process as shown in Scheme 2.

\subsubsection{Char analysis}


The SEM images of the residual char surfaces of VE/BF, $2 \%$ NCS-VE/BF, $4 \%$ NCS-VE/BF, and $6 \%$ NCS-VE/BF composites after horizontal burn test are shown in Fig. 7. It can be observed that the VE/BF composites showed a thin and loose flakes kind of brittle scarred char produced through quick evaporation of the condensed phase. As a result, the intensity of the fire propagation increased by allowing the two factors in the fire triangle, oxygen and heat. However, the introduction of NCS into VE/BF composites exhibited the dense and continual char formation, which may not allow flammable gases and resist the propagation of the combustion. The gradual improvement of the compact char formation could be observed with higher loadings of NCS additive. In addition, the SEM-EDX analysis presented the major elements present in the char residue of VE/BF and NCS-VE/BF composites. The VE/BF exhibited the major elements $\mathrm{C}$ and $\mathrm{O}$ refers the carbonaceous char. However, inclusion of NCS into VE/BF composites showed the Si element in the char along with $\mathrm{C}$ and $\mathrm{O}$. The \% of Si and $\mathrm{O}$ increased and decreased the \% of $\mathrm{C}$ in the char residue in 4 and 6 wt.\% of NCS-VE/BF composites which means the crystalline silica was presented in the char residue.

\subsubsection{Mechanical performance 3.2.6.1. Tensile Properties}

An evident increase in the tensile properties of the VE/BF composite was observed as a result of the NCS addition. The tensile test results are presented in Fig. 8 and Table 3, along with error bars. The tensile strength of VE/BF is enhanced by $29.5 \%$ after the inclusion of $6 \%$ NCS. The tensile strength values of the composites are in the order of $6 \% \mathrm{NCS}-\mathrm{VE} / \mathrm{BF}(36.24 \mathrm{MPa})>2 \% \mathrm{NCS}-\mathrm{VE} / \mathrm{BF}(30.73 \mathrm{MPa})>4 \% \mathrm{NCS}-$ VE/BF (30.42 MPa) > VE/BF (27.95 MPa). The inclusion of FR particles in BF-based polymer composites generally reduces their tensile strength and interfacial bonding due to the particles non compatibility with the fibers and polymers; this has been frequently reported in the literature (Fang et al. 2020; Liu et al. 2012). However, in this study, the NCS particles enhance the interfacial bonding of the BFs with VE, and hence, increase the tensile strength of the composites. This increase in the tensile strength supports -OH interactions between the NCS particles and VE/BF composites, as revealed in the FTIR analysis. These results also verify the fine dispersion of the NCS particles in the composites, as evident from the SEM images of the composite surfaces. The deposition of the NCS particles on the BF surfaces enhances the interfacial bonding with the VE matrix, which results in a reduced number of fiber pull-outs during the tensile fracture, as is evident from the SEM fractographs in Fig. 5. The decrease in the fiber pull-out spots in the NCS-filled VE/BF composites indicates enhanced interfacial bonding between the fibers and the matrix. The friction at the interfaces between the fibers and the matrix in the presence of NCS facilitates the transfer of load from the matrix to the fibers, thereby causing a dominant fiber breakout failure instead of fiber pull-outs.

The higher stiffness of the NCS particles compared to those of BFs and VE also shows its effect in the form of the higher tensile modulus of the NCS-filled VE/BF composites. The results indicate that the tensile modulus of the VE/BF composite increases after the incorporation of the NCS particles. The tensile moduli of the composites are in the order of $6 \%$ NCS-VE/BF $(2.38 \mathrm{GPa})>4 \% \mathrm{NCS}-\mathrm{VE} / \mathrm{BF}(1.76$ 
$\mathrm{GPa})>2 \% \mathrm{NCS}-\mathrm{VE} / \mathrm{BF}(1.68 \mathrm{GPa})>\mathrm{VE} / \mathrm{BF}(1.57 \mathrm{GPa})$. The increase in the tensile modulus is as before attributed to the enhanced interfacial bonding between the fibers and the matrix in the presence of NCS particles. In the NCS-filled VE/BF composites, the load is largely transferred to the BFs, which has a higher tensile modulus than that of the VE matrix, causing the tensile moduli of these composites to increase. A similar trend is reported in the literature regarding the tensile moduli of other particulate-filled NF composite materials (Chee et al. 2021; Beigloo et al. 2020).

\subsubsection{Flexural Properties}

An increase in the flexural properties was observed after incorporating NCS particles into the VE/BF composite. The results of the three-point bending test are summarized in Fig. 8 and Table 3 . The maximum flexural strength is observed after incorporating $4 \%$ NCS particles into the VE/BF composite. The increase in the flexural strength of the $4 \%$ NCS-VE/BF composite is $15.5 \%$ of that of the VE/BF composite. The flexural strengths of the composites follow the order $4 \%$ NCS-VE/BF $(135.9 \mathrm{MPa})>2 \%$ NCS-VE/BF (122.89 MPa) > VE/BF (117.53 MPa) > 6\% NCS-VE/BF (63.32 MPa). The same reason explains the increase in the flexural strength of the composites as that for the increase in the tensile strength. The compatibility of NCS particles, their interaction with BFs, and the fine distribution of the particles in the VE resin enhance the interfacial bonding between the resin and the reinforcement. The distribution of NCS particles in the VE/BF composite can be seen in the SEM images of composite surfaces in Fig. 4. The interaction of NCS with the VE/BF composite is explained based on the FTIR analysis results. A decrease in the flexural strength of the VE/BF composite is observed after NCS loading exceeds $4 \mathrm{wt} \%$. The $6 \%$ NCS-VE/BF composite has the lowest flexural strength. The low flexural strength at a high loading of NCS particles in the VE/BF composite may be attributed to the agglomeration of the particles, causing a higher stress concentration.

The flexural modulus of the composites also increases after loading the NCS particles in the VE/BF composite. The $4 \mathrm{wt} \%$ NCS-incorporated VE/BF composite displays the highest flexural modulus, which is 2.33 times that of the basic VE/BF composite. The flexural modulus of the composites follow the order 4\% NCS-VE/BF (18.01 GPa) > 2\% NCS-VE/BF (14.68 GPa) > VE/BF (7.7 GPa) > 6\% NCS-VE/BF $(2.2$ $\mathrm{GPa}$ ). The increase in the flexural modulus of the VE/BF composite after the incorporation of NCS is attributed to the compatibility and enhanced interfacial bonding. The higher flexural and tensile moduli also ensure higher thermal stability of the VE/BF composites in the presence of NCS particles.

\subsubsection{Impact Properties}

The ability of the VE/BF composites to absorb energy before impact failure was observed to increase after the incorporation of NCS particles. The results of the Izod impact test are summarized in Fig. 8 and Table 3. The VE/BF composite with $4 \mathrm{wt} \%$ NCS particles absorbs the highest amount of energy in the impact test, which is $53 \%$ of that of the VE/BF composite. The composites absorb the impact energy in the following order: $4 \%$ NCS-VE/BF $(0.0314 \mathrm{~J} / \mathrm{mm})>2 \% \mathrm{NCS}-\mathrm{VE} / \mathrm{BF}(0.0306 \mathrm{~J} / \mathrm{mm})>6 \% \mathrm{NCS}-\mathrm{VE} / \mathrm{BF}$ $(0.026 \mathrm{~J} / \mathrm{mm})>V E / B F(0.0205 \mathrm{~J} / \mathrm{mm})$. The impact properties of the composites decrease after NCS loading exceeds $4 \mathrm{wt} \%$. The $6 \%$ NCS-VE/BF composite absorbs lower impact energy than the other NCS- 
filled VE/BF composites; may be due to the agglomeration of particles, which causes stress concentration, hence, rapid failure. The rigidity of the NCS particles as compared to the VE resin also enhances the impact properties of the VE/BF composites. A similar trend regarding the enhancement in the impact properties of NF-based polymer composites caused by FR particles is reported in the literature (Raghul et al. 2020; Bozkurt et al. 2017).

\subsubsection{Fracture morphology}

No noticeable changes were observed among the composites in the fracture micrographs, except for the resin's coarse surface responsible for the filler addition and the nonwoven fabric fracture behavior. The interfacial bonding between the fibers and the matrix was marginally weak, and few fiber pullouts were observed in the VE/BF composites. However, the filler-loaded resin improved the interfacial bonding in the composites and tightly adhered to the fibers. Thus, the fiber breakage is preponderated over the fiber and matrix interfacial failure described in the FTIR and mechanical section.

\section{Conclusions}

In this study, chitosan was successfully modified to a superior FR and thermally stable form (NCS) by a simple chemical method. Characterization techniques such as SEM, elemental analysis, FTIR, XRD, TGA, and microcalorimetry proved the chemical formation of NCS and its thermal and FR properties. NCSVE/BF composites showed satisfactory flame retardancy and thermal stability compared to VE/BF composites: delay burn time of approximately $40 \%$, enhanced LOI about $33 \%$ and HRR decrease of roughly $14 \%$, and TGA data showed $9 \mathrm{wt} . \%$ at $700^{\circ} \mathrm{C}$. Interestingly, incorporating the NCS additive significantly improved the tensile, flexural, and impact properties of the VE/BF composites. Furthermore, SEM analysis demonstrated a homogeneous distribution of the additives, which was the main factor responsible for changing the properties of the composites. In summary, the above results confirmed that NCS could be used as an FR in NFs composites with improved mechanical strength and thermal stability.

\section{Declarations}

\section{Acknowledgments}

This study was supported by the Basic Science Research Program through the National Research Foundation of Korea (NRF) funded by the Ministry of Science Education (2018R1A6A1A03024509 and 2021R1A2B5B03002355).

\section{Ethics declarations}

Conflict of interest

The authors declare no conflict of interest.

\section{Animal Studies}


The authors carried out no animal or human studies.

\section{Consent to participate}

All the authors give explicit consent to participate and submit the article.

\section{Consent for publication}

The authors obtained consent for publication from the responsible authorities at the institute where the work has been carried out.

\section{Ethics approval}

All the authors agree with the content of the article.

\section{References}

1. Atta Ur Rehman S, Prabhakar MN, Wang H, Song J (2018) The influence of particle size and surface treatment of filler on the properties of oyster shell powder filled polypropylene composites 39:24202430. https://doi.org/10.1002/pc.24225

2. Beigloo JG, Khademi Eslam H, Hemmasi AH et al (2020) Nanographene's influence on a recycled high-density polyethylene/poplar wood flour nanocomposite. BioResources 15:1233-1251. https://doi.org/10.15376/biores.15.1.1233-1251

3. Bozkurt ÖY, Özbek Ö, Abdo AR (2017) The effects of nanosilica on charpy impact behavior of glass/epoxy fiber reinforced composite laminates. Period Eng Nat Sci 5. https://doi.org/10.21533/pen.v5i3.119

4. Budnyak T, Tertykh V, Yanovska E (2014) Chitosan immobilized on silica surface for wastewater treatment. Mater Sci 20:177-182. https://doi.org/10.5755/j01.ms.20.2.4975

5. Chalapathi KV, Song J, Prabhakar MN (2020) Impact of surface treatments and hybrid flame retardants on flammability, and thermal performance of bamboo fabric composites. J Nat Fibers:111. https://doi.org/10.1080/15440478.2020.1798849

6. Chee SS, Jawaid M, Alothman OY, Fouad H (2021) Effects of nanoclay on mechanical and dynamic mechanical properties of bamboo/kenaf reinforced epoxy hybrid composites. Polymers 13:395. https://doi.org/10.3390/polym13030395

7. Costes L, Laoutid F, Brohez S, Dubois $P$ (2017) Bio-based flame retardants: When nature meets fire protection. Mater Sci Eng R Rep 117:1-25. https://doi.org/10.1016/j.mser.2017.04.001

8. Elsabbagh A, Attia T, Ramzy A et al (2018) Towards selection chart of flame retardants for natural fibre reinforced polypropylene composites. Compos B Eng 141:1-8. https://doi.org/10.1016/j.compositesb.2017.12.020

9. Fang L, Lu X, Zeng J et al (2020) Investigation of the flame-retardant and mechanical properties of bamboo fiber-reinforced polypropylene composites with melamine pyrophosphate and aluminum 
hypophosphite addition. Materials (Basel) 13:479. https://doi.org/10.3390/ma13020479

10. Hamdani S, Longuet C, Perrin D et al (2009) Flame retardancy of silicone-based materials. Polym Degrad Stab 94:465-495. https://doi.org/10.1016/j.polymdegradstab.2008.11.019

11. Hassan H, Salama A, El-Ziaty AK, El-Sakhawy M (2019) New chitosan/silica/zinc oxide nanocomposite as adsorbent for dye removal. Int J Biol Macromol 131:520-526. https://doi.org/10.1016/j.ijbiomac.2019.03.087

12. Hung X, Cen D, Wei R, Fan Hualin, Bao Z (2019) Synthesis of Porous Si/C composite Nanosheets from Vermuculite with a Hierarchical Strcture as a High performance Anode for Lithium-ion Battery. ACS Appl Mater Interfaces 11:26854-26862. https://doi.org/10.1021/acsami.9b06976

13. Jeencham R, Suppakarn N, Jarukumjorn K (2014) Effect of flame retardants on flame retardant, mechanical, and thermal properties of sisal fiber/polypropylene composites. Compos B Eng 56:249253. https://doi.org/10.1016/j.compositesb.2013.08.012

14. Khalili P, Tshai KY, Kong I (2017) Natural fiber reinforced expandable graphite filled composites: Evaluation of the flame retardancy, thermal and mechanical performances. Compos A 100:194-205. https://doi.org/10.1016/j.compositesa.2017.05.015

15. Kim NKyeun, Bruna FG, Das 0 et al (2020) Fire-retardancy and mechanical performance of proteinbased natural fibre-biopolymer composites. Compos $\mathrm{C} 1$. https://doi.org/10.1016/j.jcomc.2020.100011

16. Kumar S, Koh J (2012) Physiochemical, optical and biological activity of chitosan-chromone derivative for biomedical applications. Int J Mol Sci 13:6102-6116. https://doi.org/10.3390/ijms13056102

17. Kuranchie C, Yaya A, Bensah YD (2021) The effect of natural fibre reinforcement on polyurethane composite foams - A review. Sci Afr 11:e00722. https://doi.org/10.1016/j.sciaf.2021.e00722

18. Lau K-T, Hung P-Y, Zhu M-H, Hui D (2018) Properties of natural fibre composites for structural engineering applications. Compos B Eng 136:222-233.

https://doi.org/10.1016/j.compositesb.2017.10.038

19. Li P, Liu C, Xu Y-J et al (2020) Novel and eco-friendly flame-retardant cotton fabrics with lignosulfonate and chitosan through LbL: Flame retardancy, smoke suppression and flame-retardant mechanism. Polym Degrad Stab 181. https://doi.org/10.1016/j.polymdegradstab.2020.109302

20. Liu SJ, Han YM, Zhu RX et al (March 2012) Effect of flame retardant on combustion and mechanical properties of bamboo-fiber based composites. Adv Mater Res 488-489:597-601. https://doi.org/10.4028/www.scientific.net/AMR.488-489.597

21. Lustriane C, Dwivany FM, Suendo V, Reza M (2018) Effect of chitosan and chitosan-nanoparticles on post harvest quality of banana fruits. J Plant Biotechnol 45:36-44. https://doi.org/10.5010/JPB.2018.45.1.036

22. Pan M, Mei Changtong, Du J, Li G (2014) Synergistic effect of Nano silicon dioxide and ammonium polyphosphate on flame retardancy of wood fiber-polyethylene composites. Compos A 66:128-134. https://doi.org/10.1016/j.compositesa.2014.07.016 
23. Porsche Newsroom (2019) New Porsche 718 Cayman GT4 Clubsport featuring natural-fibre body panels https://newsroom.porsche.com/en/products/porsche-world-premiere-new-718-cayman-gt4clubsport-16733.html

24. Prabhakar MN, Raghavendra GM, Vijaykumar BVD et al (2019) Synthesis of a novel compound based on chitosan and ammonium polyphosphate for flame retardancy applications. Cellulose 26:8801-8812. https://doi.org/10.1007/s10570-019-02671-y

25. Prabhakar MN, Song J (2020) Influence of chitosan-centered additives on flammable properties of vinyl ester matrix composites. Cellulose 27:8087-8103. https://doi.org/10.1007/s10570-020-033134

26. Prabhakar MN, Song Jl (2018) Fabrication and characterisation of starch/chitosan/flax fabric green flame-retardant composites. Int J Biol Macromol 119:1335-1343. https://doi.org/10.1016/j.ijbiomac.2018.07.006

27. Raghul KS, Logesh M, Kisshore RK et al (2021) Mechanical behaviour of sisal palm glass fiber reinforced composite with addition of Nano silica. Mater Today Proc 37:1427-1431. https://doi.org/10.1016/j.matpr.2020.07.063

28. Sain M, Park SH, Suhara F, Law S (2004) Flame retardant and mechanical properties of natural fibre-PP composites containing magnesium hydroxide. Polym Degrad Stab 83:363-367. https://doi.org/10.1016/S0141-3910(03)00280-5

29. Sathees Kumar S (2020) Dataset on mechanical properties of natural fiber reinforced polyester composites for engineering applications. Data Brief 28:105054. https://doi.org/10.1016/j.dib.2019.105054

30. Sefadi JS, Luyt AS (2012) Morphology and properties of EVA/empty fruit bunch composites. J Thermoplast Compos Mater 25:895-914. https://doi.org/10.1177/0892705711421806

31. Shao ZB, Deng C, Tan Y, Yu L, Chen MJ, Chen L, Wang YZ (2014) Ammonium polyphosphate chemically modified with ethanolamine as an efficient intumescent flame retardant for polypropylene. J Mater Chem A 2:13955-13965. DOI:10.1039/c4ta02778g

32. Shao N, Qu Y, Hu Y, Tian Z, Gao Y, Zhu X (2021) Effect of starch-based flame retardant on the thermal degradation and combustion properties of reconstituted tobacco sheet. Cellulose 28:741-755

33. Shen Y, Zhao P, Shao Q (2014) Porous silica and carbon derived materials from rice husk pyrolysis char. Micropor Mesopor Mater 188:46-76. https://doi.org/10.1016/j.micromeso.2014.01.005

34. Song S, Ma J, Cao K, Chang G, Huang Y, Yang J (2014) Synthesis of a novel dicyclic silicon-/phosphorus hybrid and its performance on flame retardancy of epoxy resin. Polym Degrad Stab 99:43-52. https://doi.org/10.1016/j.polymdegradstab.2013.12.013

35. Shukor F, Hassan A, Saiful Islam Md et al (2014) Effect of ammonium polyphosphate on flame retardancy, thermal stability and mechanical properties of alkali treated kenaf fiber filled PLA biocomposites. Mater Des (1980-2015) 54:425-429. https://doi.org/10.1016/j.matdes.2013.07.095

36. Wang J, Yang Shanye, Ma R (2020) Synthesis and characterization of sodium laurylsulfonate modified silicon dioxide for the efficient removal of europium. J Mol Liq 316. 
https://doi.org/10.1016/j.molliq.2020.113846

37. Wu Yingji, Cai L, Mei C et al (2020) Development and evaluation of zinc oxide-blended kenaf fiber biocomposite for automotive applications. Mater Today Commun 24.

https://doi.org/10.1016/j.mtcomm.2020.101008

38. Yeh J-T, Chen C-L, Huang K-S (2007) Synthesis and properties of chitosan/SiO2 hybrid materials. Mater Letter 61:1292-1295. doi:10.1016/j.matlet.2006.07.016

\section{Tables}

Table 1. TGA results of VE/BF and NCS-VE/BF composites

\begin{tabular}{|c|c|c|c|c|c|c|}
\hline \multirow[t]{4}{*}{ Sample } & \multicolumn{6}{|c|}{ Thermogravimetric analysis } \\
\hline & \multicolumn{3}{|l|}{ Nitrogen } & \multicolumn{3}{|l|}{ Air } \\
\hline & $\mathrm{T}_{\text {onset }}$ & $\mathrm{T}_{\max }$ & Residue wt.\% @ & $\mathrm{T}_{\text {onset }}$ & $\mathrm{T}_{\max }$ & Residue wt.\% @ \\
\hline & $10 \%\left[{ }^{\circ} \mathrm{C}\right]$ & $75 \%\left[{ }^{\circ} \mathrm{C}\right]$ & $700^{\circ} \mathrm{C}$ & $10 \%\left[{ }^{\circ} \mathrm{C}\right]$ & $75 \%\left[{ }^{\circ} \mathrm{C}\right]$ & $700^{\circ} \mathrm{C}$ \\
\hline VE/BF & 341 & 454 & 4.7 & 317 & 393 & 0 \\
\hline $\begin{array}{l}\text { 2\%NCS- } \\
\text { VE/BF }\end{array}$ & 341 & 457 & 6.8 & 317 & 409 & 0 \\
\hline $\begin{array}{l}4 \% \text { NCS- } \\
\text { VE/BF }\end{array}$ & 341 & 456 & 8.2 & 324 & 421 & 1.2 \\
\hline $\begin{array}{l}\text { 6\%NCS- } \\
\text { VE/BF }\end{array}$ & 336 & 454 & 9.0 & 306 & 417 & 1.3 \\
\hline
\end{tabular}

Table 2. UL-94, LOI, micro and calorimetry results of VE/BF and NCS-VE/BF composites

\begin{tabular}{|c|c|c|c|c|c|c|c|c|}
\hline \multirow[t]{3}{*}{ Sample } & \multicolumn{2}{|c|}{ Horizontal Burn Test } & \multicolumn{2}{|c|}{ VB Test } & LOI & \multicolumn{3}{|c|}{ Calorimeter } \\
\hline & \multicolumn{4}{|l|}{ Air } & \multicolumn{4}{|c|}{$\mathrm{O}_{2}+\mathrm{N}_{2}$} \\
\hline & $\begin{array}{l}\text { Burn time } \\
\text { [sec] }\end{array}$ & $\begin{array}{l}\text { Burn rate } \\
{[\mathrm{mm} / \mathrm{sec}]}\end{array}$ & Dripping & Rating & $(\%)$ & $\begin{array}{l}\mathrm{pHRR} \\
{[\mathrm{W} / \mathrm{g}]}\end{array}$ & $\begin{array}{l}\text { THR } \\
{[\mathrm{kj} / \mathrm{g}]}\end{array}$ & $\begin{array}{l}\text { FIGRA } \\
\mathrm{W} / \mathrm{g} \cdot \mathrm{s}^{-1}\end{array}$ \\
\hline VE/BF & 1.53 & 0.66 & $\mathrm{~N}$ & NR & 18.9 & 422.7 & 25.5 & 0.92 \\
\hline $2 \%$ NCS-VE/BF & 2.32 & 0.49 & $\mathrm{~N}$ & $\mathrm{HB}$ & 26.4 & 381.5 & 24.7 & 0.86 \\
\hline $4 \%$ NCS-VE/BF & 2.35 & 0.48 & $\mathrm{~N}$ & $\mathrm{HB}$ & 27.6 & 373.6 & 23.3 & 0.84 \\
\hline $6 \%$ NCS-VE/BF & 2.54 & 0.43 & $\mathrm{~N}$ & $\mathrm{HB}$ & 28.3 & 361.9 & 20.7 & 0.83 \\
\hline
\end{tabular}

Table 3. Mechanical data of VE/BF and NCS-VE/BF composites 


\begin{tabular}{|llllll|}
\hline & $\begin{array}{l}\text { Tensile } \\
\text { strength } \\
(\mathrm{MPa})\end{array}$ & $\begin{array}{l}\text { Tensile } \\
\text { Modulus } \\
(\mathrm{GPa})\end{array}$ & $\begin{array}{l}\text { Flexural } \\
\text { strength } \\
(\mathrm{MPa})\end{array}$ & $\begin{array}{l}\text { Flexural } \\
\text { Modulus } \\
(\mathbf{G P a})\end{array}$ & $\begin{array}{l}\text { Impact } \\
\text { strength } \\
(\mathrm{J} / \mathrm{mm})\end{array}$ \\
\hline VE/BF & 27.95 & 1.57 & 117.53 & 7.70 & 0.0205 \\
\hline $\begin{array}{l}2 \% \text { NCS- } \\
\text { VE/BF }\end{array}$ & 30.73 & 1.68 & 122.89 & 14.68 & 0.0306 \\
\hline $\begin{array}{l}4 \% \text { NCS- } \\
\text { VE/BF }\end{array}$ & 30.42 & 1.76 & 151.65 & 18.01 & 0.0314 \\
\hline $\begin{array}{l}6 \% \text { NCS- } \\
\text { VE/BF }\end{array}$ & 26.29 & 2.36 & 63.32 & 2.66 & 0.0260 \\
\hline
\end{tabular}

Figures

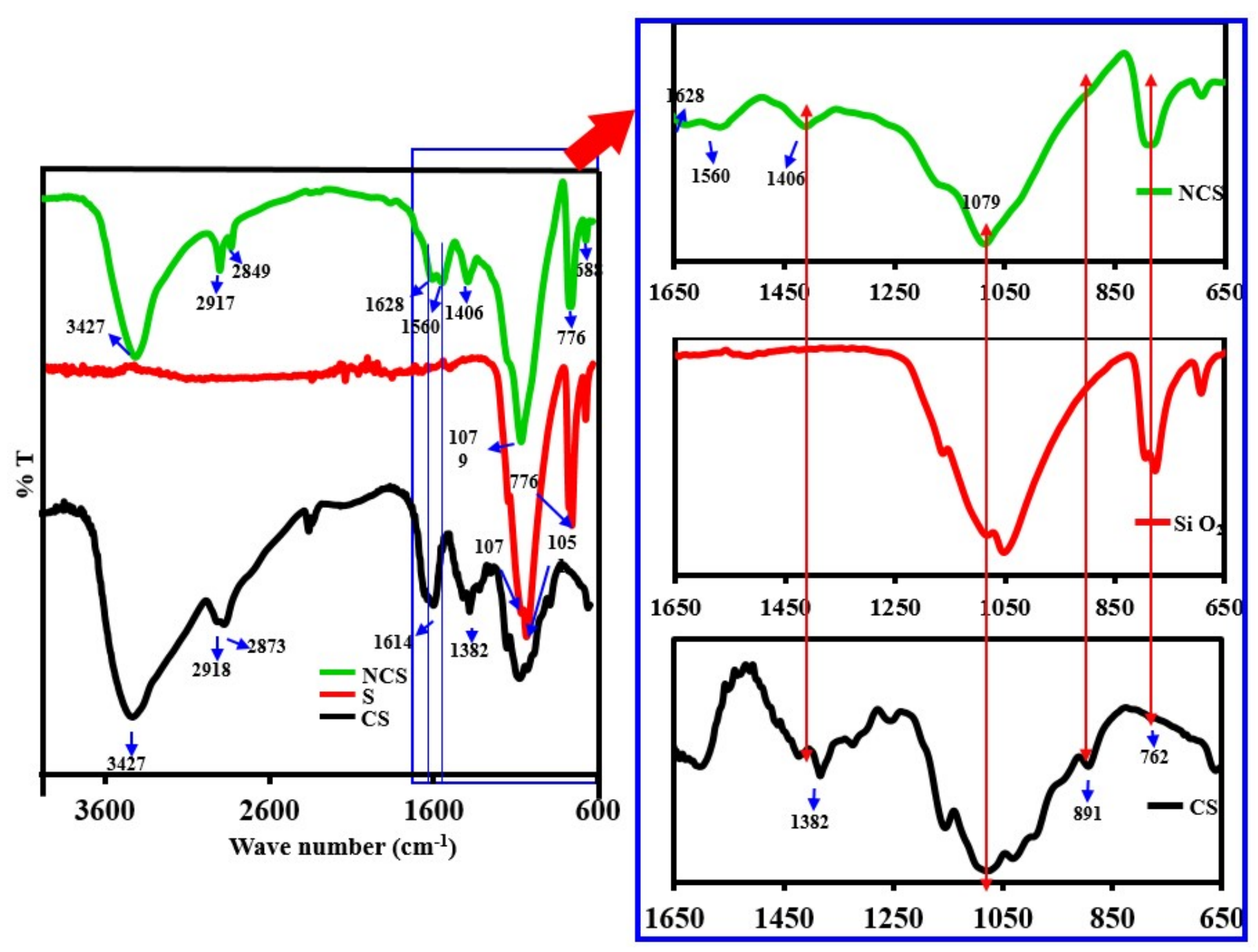

Figure 1 
Spectral analysis results of NCS compounds.

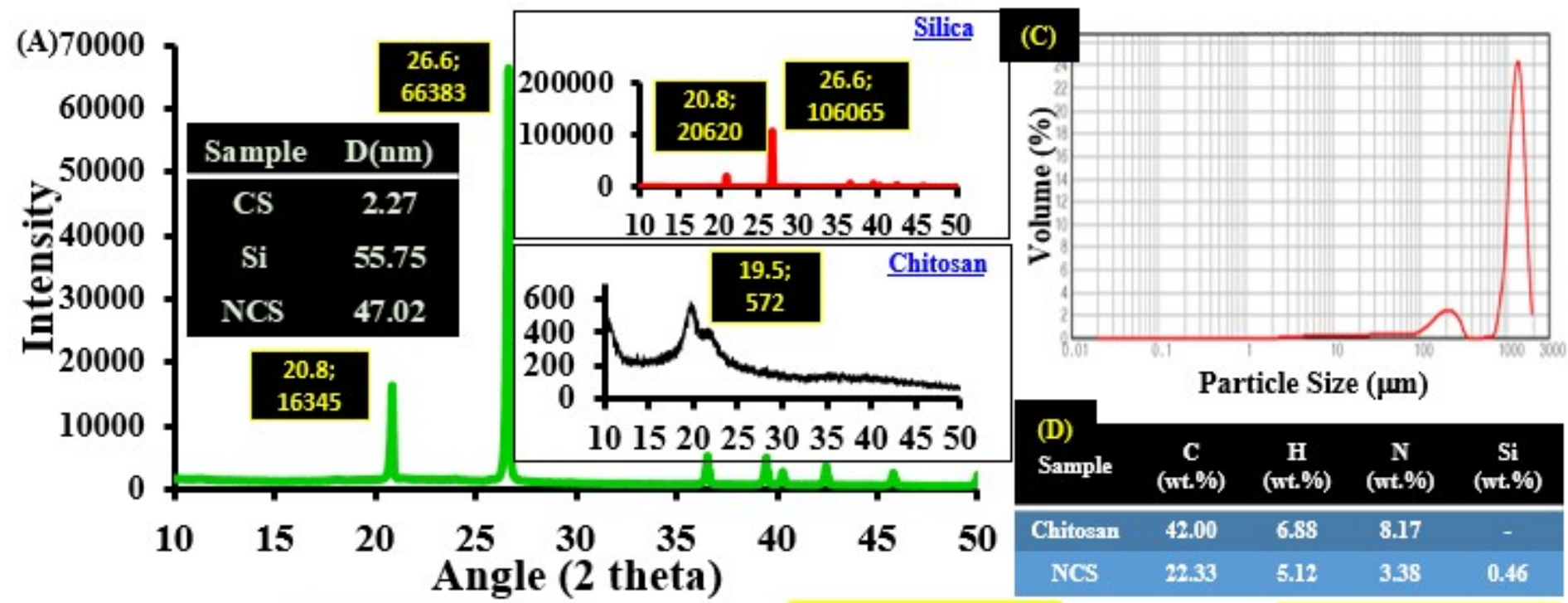

(B)
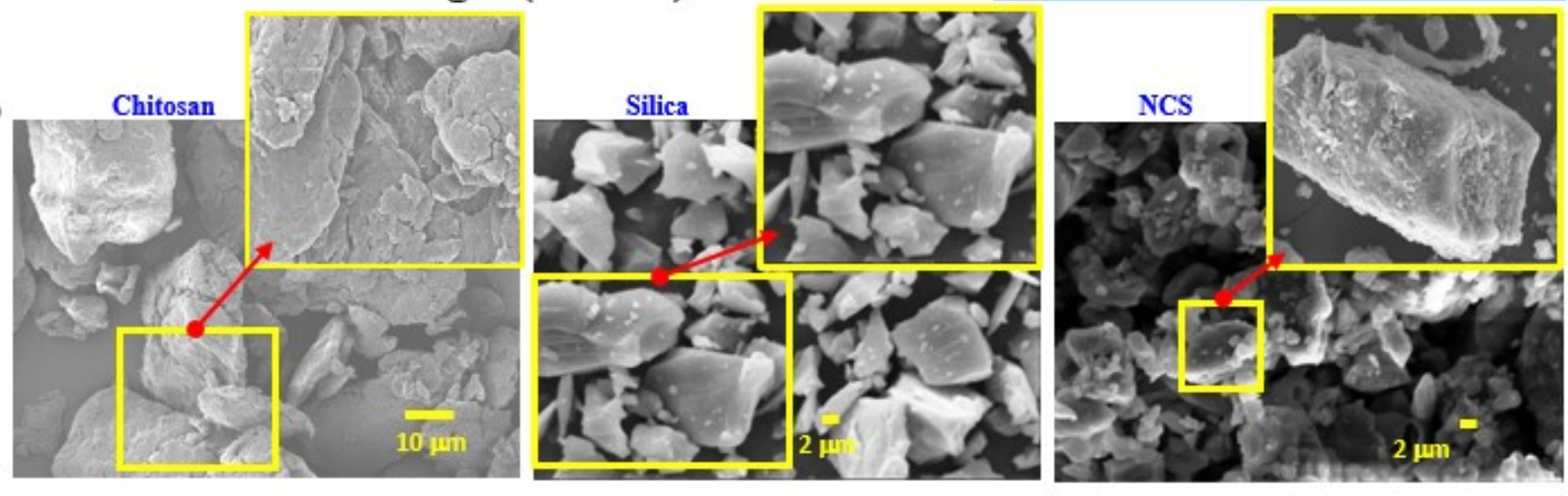

Figure 2

(A) Powder XRD analysis, (B) SEM micrographs, (C) Particle size analysis, and (D) Elemental analysis results of chitosan and NCS compounds. 

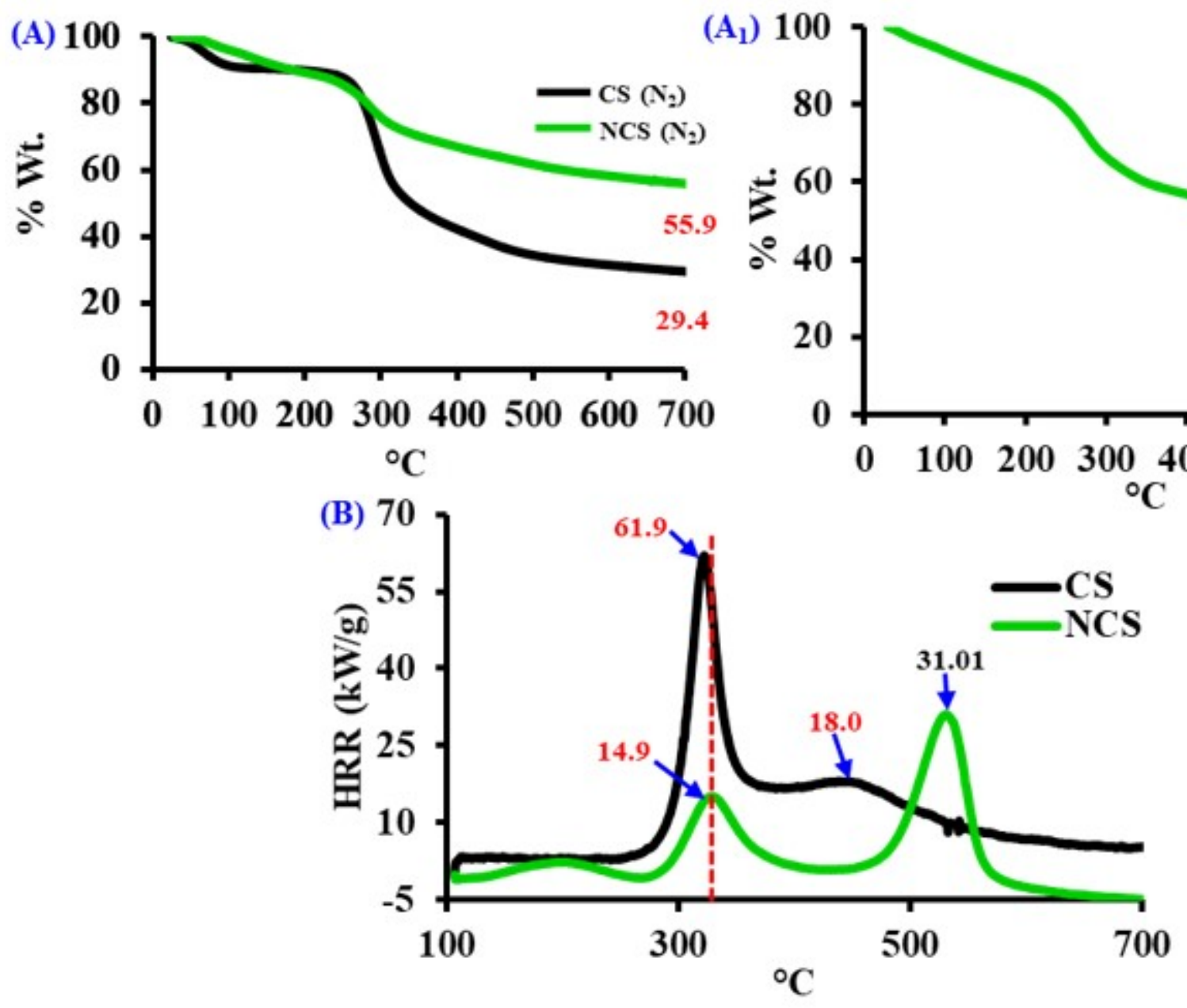

Figure 3

(A) TGA (N2), (A1) TGA (Air), and (B) Microcalorimeter profiles of NCS compounds. 


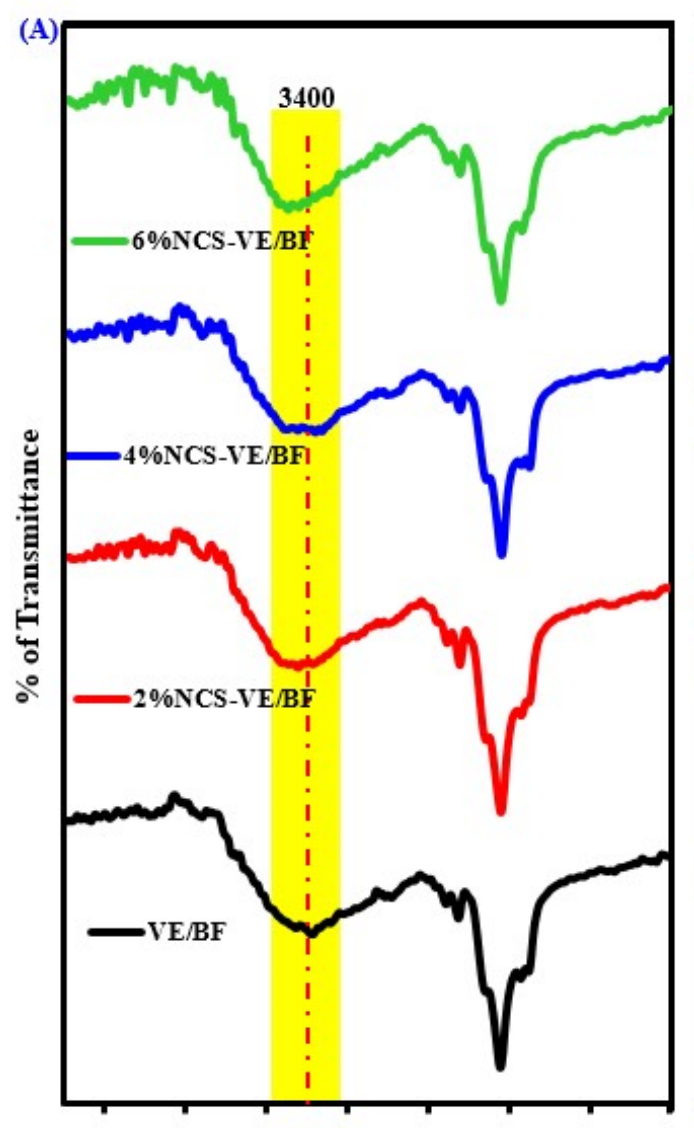

390037003500330031002900270025001600 Wavenumber $\left(\mathrm{cm}^{-1}\right)$
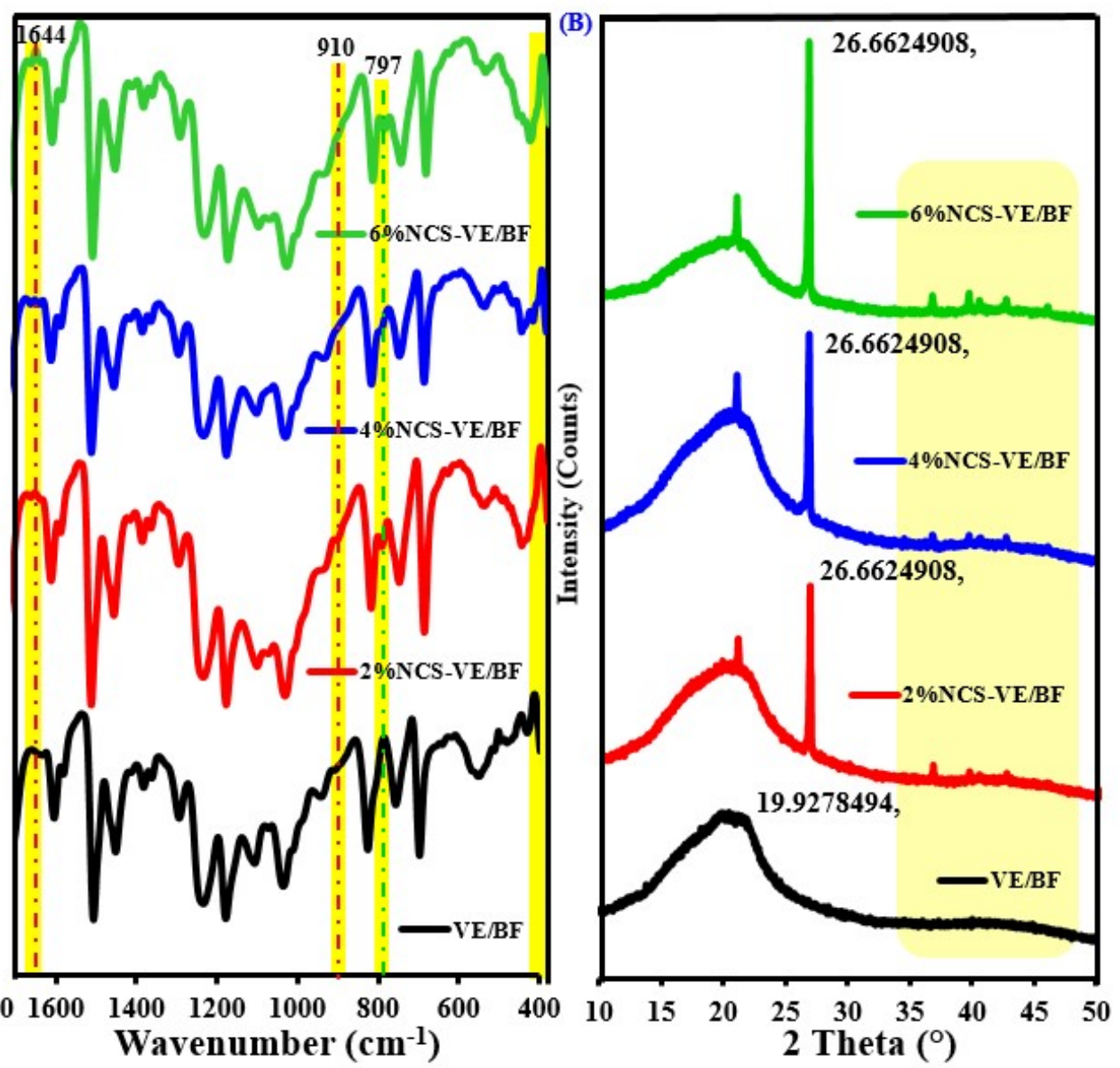

Figure 4

(A) FTIR spectra and (B) Powder XRD spectra of VE/BF and NCS-VE/BF composites. 


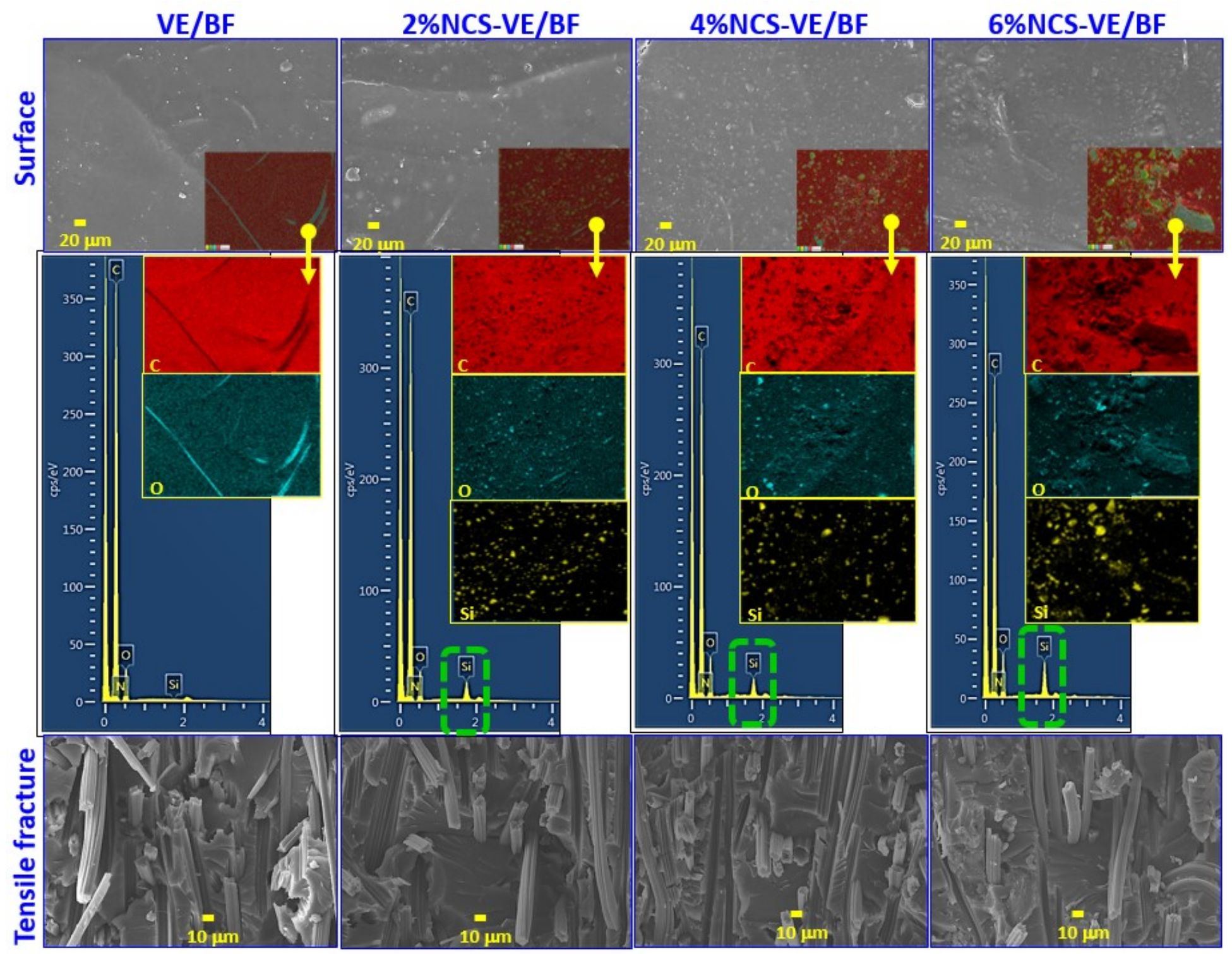

Figure 5

SEM micrographs of surfaces and tensile fracture surfaces of VE/BF and NCS-VE/BF composites. 

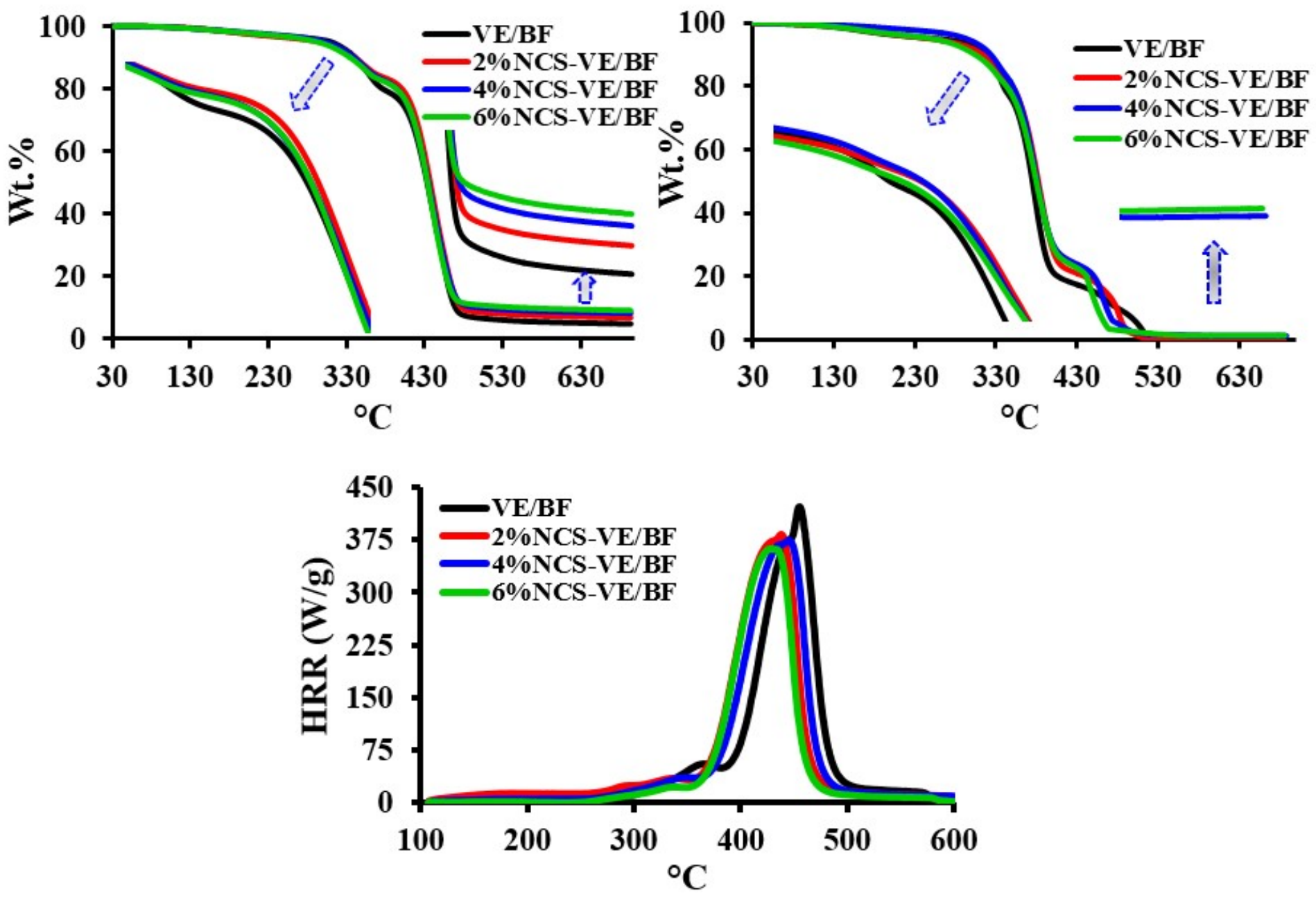

Figure 6

TGA profiles of VE/BF and NCS-VE/BF composites under N2 and air atmosphere.

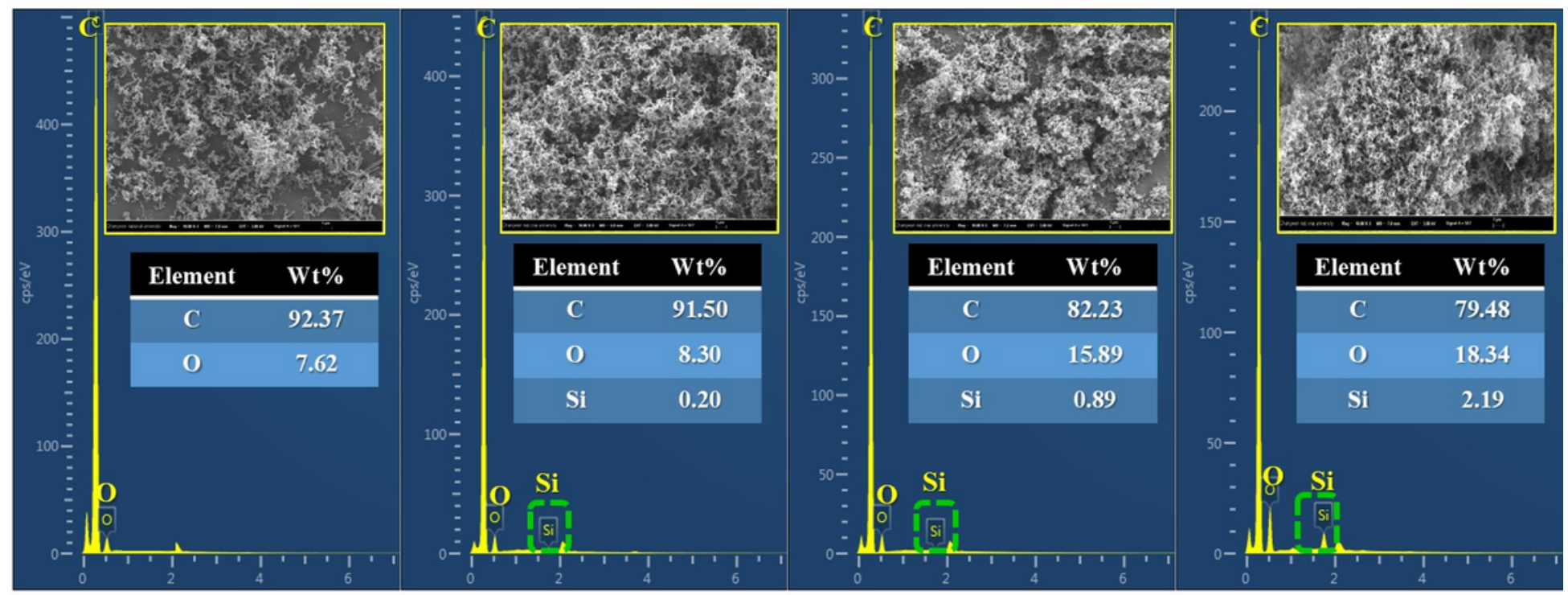

Figure 7 
Char micro and EDX analysis results of VE/BF and NCS-VE/BF composites.
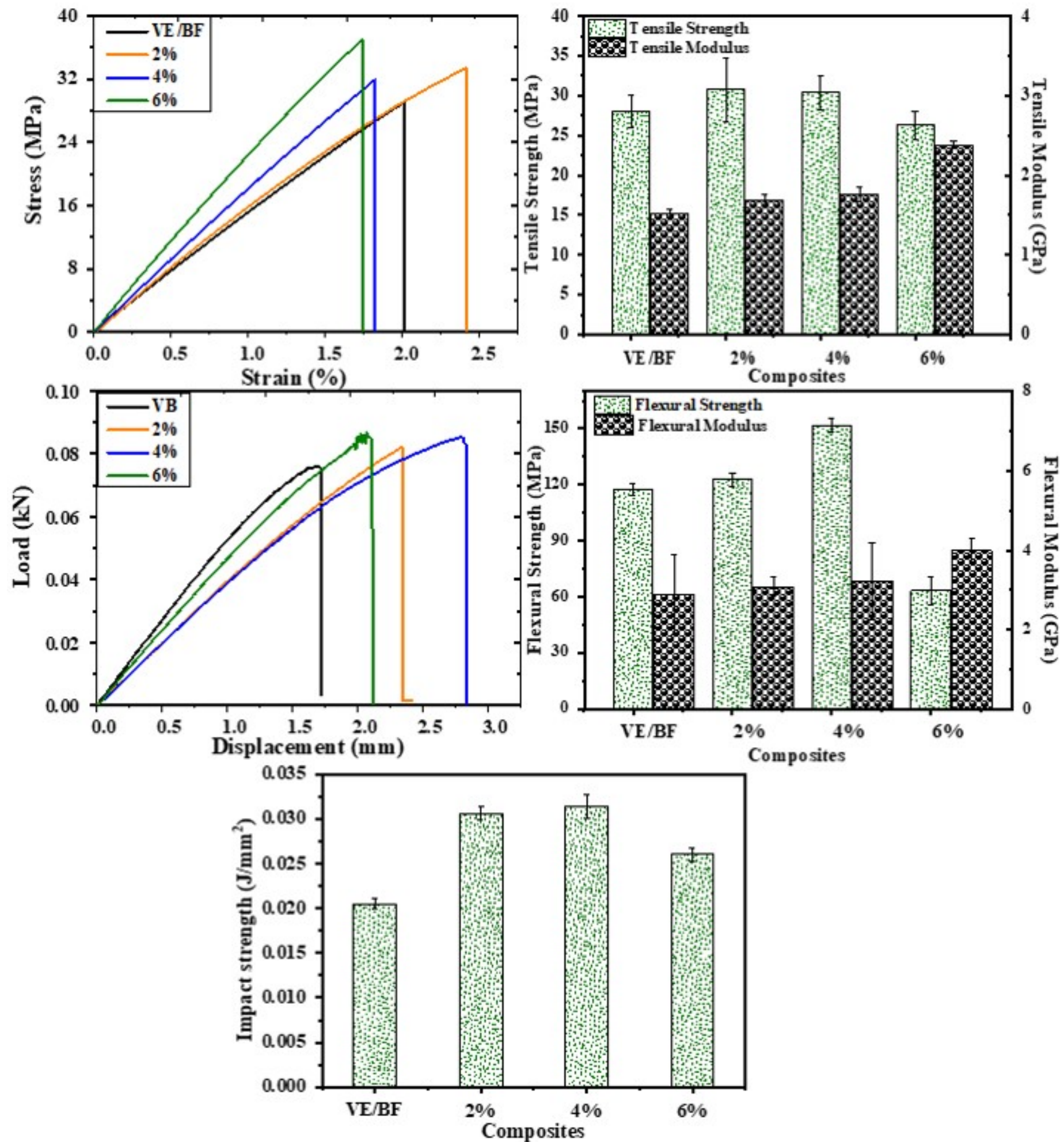

Figure 8

Char micro and EDX analysis results of VE/BF and NCS-VE/BF composites.

\section{Supplementary Files}


This is a list of supplementary files associated with this preprint. Click to download.

- SIFig.1.jpg

- SIFig.2.jpg

- SIFig.3.jpg

- Scheme1.png

- Scheme2.png 